\title{
HUBUNGAN TEKANAN DARAH DENGAN PERNAFASAN BAYI BARU LAHIR
}

\author{
Mariah Ulfah \\ ${ }^{1}$ Prodi Kebidanan D3, STIKes Harapan Bangsa Purwokerto \\ email: maydaanzili@gmail.com
}

\begin{abstract}
The physiological changes that occur in neonates heaviest is the transmission of the placenta into the fetal circulation or respiration independently. Factors affecting the normal transmission of this or that increases asphyxia (state hypoxemia, hypercapnia, and acidosis) fetus will affect the adjustment of the fetus to life extrauterine Interference in breathing can occur there is a new baby is born, one of which is caused by a factor mother of them are related with blood pressure is hypotension or preeclampsia (Masyita Dea, 2014) Based on the pre-survey conducted on February 1 until March 4, 2016 in General Hospital Cilacap shows there are 221 maternal, from record data medic there were nearly $9.95 \%$ of maternal disease associated with blood pressure that is consecutive gestational hypertension 6 cases, severe preeclampsia 12 cases, 4 cases mild pre-eclampsia, and even two cases of HELLP syndrome to be at risk of neonatal respiratory disorders (RM Hospital Cilacap, 2016)

Objective of the research are : 1) Determine the incidence of maternal blood pressure in Cilacap General Hospital in 2016. 2) Determine the incidence of respiratory Newborn in Hospital Cilacap 2016. 3) Knowing Relations maternal blood pressure Systole with respiratory Newborn in Hospital Cilacap year 2016. 4) Knowing Relations diastolic blood pressure with respiratory maternal Newborn in Cilacap General Hospital in 2016. This study was an crossectional method and data were analyzed using Chi-square test
\end{abstract}

The results showed 1) The highest maternal age in healthy reproductive age range (20-35) is $71.3 \%$ compared to the age of $>35$ years of $20.7 \%$ and $<20$ years at $8 \% .2$ ) characteristics of respondents based on parity tertinggiadalah primipara (77.0\%) compared with multiparous (17.2\%) and Grandemultipara (5.7\%) 3) The state of maternal systolic that systolic blood pressure $<140 \mathrm{mmHg} 85 \%$ higher than the systolic blood pressure of 140-159 $\mathrm{mmHg} 11.5 \%$, systolic blood pressure>: $160 \mathrm{~mm} \mathrm{Hg}$ was 3.4\%. 4) The state of maternal bahwatekanan diastolic diastolic $<90, \mathrm{Hg}$ is the highest compared to $69.5 \%$ diastolic blood pressure of 90 $109 \mathrm{~mm} \mathrm{Hg}$ (29.3\%), and> $110 \mathrm{mmHg}$ (1.1\%). 5) The state of the newborn breathing regularly higher (58.6\%) compared to the irregular breath (41.4\%). 6) There is a relationship of systolic blood pressure with respiratory newborns

Keyword: heart failure, respiratory newborn baby, labour 


\section{PENDAHULUAN}

Perubahan fisiologis terberat yang terjadi pada neonates adalah transmisi dari sirkulasi janin atau plasenta ke respirasi independen. Factor-faktor yang mempengaruhi transmisi normal ini atau yang meningkatkan asfiksia (keadaan hipoksemia, hiperkapnia, dan asidosis) janin akan mempengaruhi penyesuaian janin terhadap kehidupan ekstrauterin (Muliawati, 2015).

Pernapasan awal bayi baru lahir dipicu oleh faktor-faktor fisik, sensorik, dan kimia. Faktor fisik meliputi usaha yang diperlukan untuk mengembangkan paru-paru dan mengisi alveolus yang kolaps (misalnya perubahan dalam gradien tekanan). Faktor-faktor sensorik dalam adaptasi pernapasan bayi baru lahir meliputi suhu, bunyi, cahaya, suara, dan penurunan suhu, sedangkan faktor kimia meliputi perubahan dalam darah misalnya, penurunan kadar $\mathrm{O}_{2}$, peningkatan kadar $\mathrm{CO}_{2}$, dan penurunan $\mathrm{pH}$ sebagai akibat asfiksia sementara selama kelahiran. Frekuensi pernapasan bayi baru lahir berkisar antara 30 sampai 60 kali per menit (Barbara, 2004).

Paru-paru neonates mengakami pengembangan pada menit-menit pertama kelahiran dan kemudian disusul dengan pernafasan teratur, namun bila terjadi gangguan pertukaran gas oksigen dari ibu ke janin akan memicu terjadinya asfisia pada neonates atau janin (cuningham, 2006)

Gangguan pada pernafasan dapat terjadi ada bayi baru lahir. Sindrom gangguan pernapasan sering disertai riwayat asfiksia pada waktu lahir atau gawat janin pada akhir kehamilan. Gangguan pernafasan tersebut atau yang disebut asfiksia bisa disebabkan oleh factor ibu, factor bayi dan factor plasenta. Factor ibu diantaranya adalah yang berkaitan dengan tekanan darah yaitu hipotensi atau preeklamsi (Masyita Dea, 2014)

Tekanan darah ibu hamil yang tinggi juga dapat mengakibatkan gangguan pertumbuhan janin intrauterin dan juga terjadi penurunan perfusi jaringan dan organ ini disebabkan oleh menurunnya perfusi uteroplasenta, vasopasme, dan kerusakan sel endotel pembuluh darah plasenta. Sedangkan pada ibu yang tekanan darahnya normal, tidak ditemukan kelainan-kelainan tersebut sehingga perfusi nutrisi dan oksigen untuk pertumbuhan janin menjadi adekuat. Disamping itu, hasil penelitian menyebutkan bahwa neonates dengan ibu eklampsi memiliki sel darah merah berinti lebih banyak disbanding neonates normal dan ini dihubungkan dengan asfiksia 
(bayrfam, 2010).

Prognosis ibu dengan hipertensi esensial berat dan kehamilan kurang baik. Prognosis bagi janin disebabkan oleh siklus utero placenta yang kurang baik pada hipertensi berat. Janin tumbuh kurang wajar (dismaturitas), dilahirkan premature atau bahkan mati dalam kandungan. Hipertensi selama kehamilan dan persalinan tidak seperti hipertensi yang terjadi pada umumnya, tetapi mempunyai kaitan erat dengan angka kesakitan dan kematian yang tinggi lebih baik pada janin maupun ibu. Komplikasi pada umumnya terjadi pada ibu adalah perdarahan otak, gagal hati, dan ginjal akut. Janin mempunyai risiko prematur, berat badan lahir rendah, kematian serta asfiksia (Faiqoah, 2013).

Angka kematian bayi di Indonesia saat ini masih tergolong tinggi. Secara nasional berdasarkan analisa SDKI tahun 2012, tercatat 32 per 1000 kelahiran hidup, ini memang bukan gambaran yang kurang menggembirakan dibandingkan target Kemenkes yang ingin yaitu 24 ditahun 2014, juga target MDGs sebesar 23 per 1000 kelahiran hidup di tahun 2015 (SDKI, 2012). Masalah utama kematian Pada bayi dan balita adalah masa neonates (umur 0-28 hari). komplikasi yang menjadi Penyebab kemtian bayi adalah yang tertinggi asfiksia neonatorum (Profil kesehatan Indonesia, 2014).

Angka Kematian Ibu dan Angka Kematian Bayi di Kabupaten Cilacap pada tahun 2012 di Kabupaten Cilacap mencapai 28 kasus atau 95,2 per 100.000 kelahiran hidup. Tetapi pada 2012 jumlahnya meningkat menjadi 34 kasus atau 111,2 per 100.000 kelahiran hidup. Pada tahun 2014 sebanyak 36 kasus, meningkat 2 kasus dari tahun 2013 yang hanya 34 kasus, adapun penyebab angka kematian $23.5 \%$ karena masalah tekanan darah yaitu pre eklamsi dan eklampsi, meningkat pada tahun 2015 Angka Kematian Ibu berjumlah $26 \mathrm{ibu}$, dan $30,7 \%$ disebabkan karena hipertensi kehamilan dan persalian, sedangkan kematian neonatal $28.8 \%$ disebabkan karena asfiksia (Laporan Emas Kabupaten Cilacap, 2015).

Berdasarkan pra survey yang dilakukan pada tanggal 1 Februari sampai dengan 4 Maret 2016 di RSUD Cilacap menunjukan terdapat $221 \mathrm{ibu}$ bersalin, dari data rekam medic terdaat hamir $9.95 \%$ ibu bersalin mengalami penyakit berkaitan dengan tekanan darah yaitu berturut-turut gestasional hipertensi 6 kasus, preeklamsia berat 12 kasus, pre eklamsia ringan 4 kasus, bahkan 2 kasus mengalami sindrom HELLP yang akan berisiko terhadap gangguan pernafasan bayi baru lahir (RM RSUD Cilacap, 2016). 


\section{METODE PENELITIAN}

Penelitian ini dilakukan di RSUD Cilacap. Jenis penelitian adalah non eksperimental yang bertujuan untuk mengetahui hubungan antara variabel dengan desain penelitian cross sectional. Dalam penelitian ini terdapat dua variabel yang akan diteliti yaitu:

a) Variabel Bebas : tekanan darah ibu

b) Variabel terikat dalam penelitian ini adalah pernafasan bayi baru lahir

Metode pengumpulan data dengan mengambil data rekam medis.

\section{HASIL DAN PEMBAHASAN}

1. Karakteristik responden

Tabel 1. Distribusi Umur responden

\begin{tabular}{l|l|l}
\hline Umur & Frekuensi & Prosentase \\
\hline$<20$ tahun & 14 & 8.0 \\
\hline $20-35$ & 124 & 71.3 \\
\hline$>35$ tahun & 36 & 20.7 \\
\hline Total & 174 & 100 \\
\hline
\end{tabular}

Dari tabel diatas terlihat bahwa

umur ibu terbanyak di rentang usia reproduksi sehat (20-35)yaitu $71.3 \%$ dibandingkan usia >35 tahun sebesar $20.7 \%$ dan $<20$ tahun sebesar $8 \%$.
Tabel 2. Distribusi Paritas di RSUD

\begin{tabular}{|l|l|l|}
\hline Paritas & Frekuensi & Prosentase \\
\hline Primipara & 134 & 77.0 \\
\hline Multipara & 30 & 17.2 \\
\hline Grandemultipara & 10 & 5.7 \\
\hline Total & 174 & 100 \\
\hline
\end{tabular}

Dari tabel diatas terlihat bahwa karakteristik responden berdasarkan paritas yang tertinggi adalah primipara $(77.0 \%)$ dibandingkan dengan multipara (17.2\%) dan Grandemultipara (5.7\%).

Tabel 3. Keadaan Tekanan Darah Sistolik Ibu bersalin

\begin{tabular}{l|l|l}
\hline Sistolik & Frekuensi & Prosentase \\
\hline$<140 \mathrm{mmhg}$ & 148 & 85.0 \\
\hline $140-159 \mathrm{mmhg}$ & 20 & 11.5 \\
\hline$\geq 160 \mathrm{mmhg}$ & 6 & 3.4 \\
\hline Total & 174 & 100 \\
\hline \multicolumn{2}{r}{ Dari tabet diatas tertihat bahwa }
\end{tabular}

tekanan darah sistolik <140 $\mathrm{mmHg}$ lebih tinggi $85 \%$ dibandingkan dengan tekanan darah sistolik 140-159 mmhg 11.5\%, tekanan darah sistolik $\geq 160 \mathrm{mmhg}$ adalah $3.4 \%$ 
Tabel 4. Keadaan Tekanan Darah Diastolik Ibu bersalin

\begin{tabular}{l|l|l}
\hline Diastolik & Frekuensi & Prosentase \\
\hline$<90$ mmhg & 121 & 69.5 \\
\hline $\begin{array}{l}\text { 90-109 } \\
\text { mmhg }\end{array}$ & 51 & 29.3 \\
\hline $\begin{array}{l}\geq 110 \\
\text { mmhg }\end{array}$ & 2 & 1.1 \\
\hline Total & 174 & 100 \\
\hline
\end{tabular}

Dari tabel diatas terlihat bahwatekanan diastolic $<90 \mathrm{mmHg}$ adalah $69.5 \%$ terbanyak dibandingkan tekanan darah diastolic 90-109 mmhg (29.3\%), dan $>110 \mathrm{mmHg}(1.1 \%)$.

Tabel 5. Keadaan pernafasan bayi baru

\begin{tabular}{l|l|l}
\multicolumn{2}{c}{ lahir } & \multicolumn{2}{c}{ Pernafasan } & Frekuensi & Prosentase \\
\hline Teratur & 102 & 58.6 \\
\hline $\begin{array}{l}\text { Tidak } \\
\text { teratur }\end{array}$ & 72 & 41.4 \\
\hline Total & 174 & 100 \\
\hline
\end{tabular}

2. Hubungan tekanan darah sistolik dan diastolic dengan pernafasan bayi baru lahir

Tabel 6. Hubungan tekanan darah sistolik dengan pernafasan bayi baru lahir

\begin{tabular}{|c|c|c|c|c|c|c|}
\hline \multirow{3}{*}{$\begin{array}{c}\text { Tekanan } \\
\text { darah } \\
\text { sistolik }\end{array}$} & \multicolumn{6}{|c|}{ Pernafasan Bayi baru lahir } \\
\hline & \multicolumn{2}{|c|}{ Teratur } & \multicolumn{2}{|c|}{$\begin{array}{l}\text { Tidak } \\
\text { teratur }\end{array}$} & \multirow{2}{*}{$\begin{array}{c}\text { Total } \\
\mathrm{f}\end{array}$} & \multirow{2}{*}{$\%$} \\
\hline & $\mathrm{f}$ & $\%$ & $\mathrm{f}$ & $\%$ & & \\
\hline $\begin{array}{l}<140 \\
\text { mmhg }\end{array}$ & $\begin{array}{l}9 \\
9\end{array}$ & 66.89 & 49 & 33,11 & 148 & 100 \\
\hline $\begin{array}{l}\text { 140-159 } \\
\text { mmhg }\end{array}$ & 3 & 15 & 17 & 85 & 20 & 100 \\
\hline \multirow[t]{2}{*}{$\begin{array}{l}\geq 160 \\
\text { mmhg }\end{array}$} & 0 & 0 & 6 & 100 & 6 & 100 \\
\hline & \multicolumn{6}{|c|}{$\mathrm{P}$ value $=0,000$ Ho ditolak } \\
\hline
\end{tabular}


Dari tabel diatas terlihat bahwa pernafasan teratur lebih tinggi (58.6\%) dibandingkan dengan nafas yang tidak teratur (41.4\%). Tabel tersebut menunjukkan bahwa bayi baru lahri yang mempunyai pernafasan tidak teratur lebih tinggi (100\%) pada ibu bersalin dengan tekanan darah sistolik >160 mmHg, dibandingkan dengan tekanan darah sistolik 140-159 (85\%) dan tekanan darah sistolik <140 mmhg $(33,11 \%)$. Hasil uji Chi squere dengan taraf signifikasi 5\% diperoleh $p$ value 0,000 yang berarti bahwa nilai $\mathrm{p} \leq$

0,05, jadi Ho ditolak, sehingga kesimpulannya ada hubungan antara tekanan darah sistolik dengan pernafasan bayi baru lahir.

Tabel 7. Hubungan tekanan darah diastolic dengan pernafasan bayi baru lahir

\begin{tabular}{l|l|l|l|l|l|l}
\hline $\begin{array}{l}\text { Tekanan } \\
\text { darah } \\
\text { Diastolik }\end{array}$ & \multicolumn{6}{|c}{ Pernafasan Bayi baru lahir } \\
\cline { 2 - 7 } & Teratur & $\begin{array}{l}\text { Tidak } \\
\text { teratur }\end{array}$ & \multicolumn{2}{c}{ Total } \\
\cline { 2 - 7 } & $\mathrm{f}$ & $\%$ & $\mathrm{f}$ & $\%$ & $\mathrm{f}$ & $\%$ \\
\hline $\begin{array}{l}<90 \\
\text { mmhg }\end{array}$ & 91 & 75,20 & 30 & 24,80 & 121 & 100 \\
\hline $\begin{array}{l}90-110 \\
\text { mmhg }\end{array}$ & 11 & 21,57 & 40 & 78,43 & 51 & 100 \\
\hline $\begin{array}{l}\geq 110 \\
\text { mmh }\end{array}$ & 0 & 0 & 2 & 100 & 2 & 100 \\
\hline & \multicolumn{7}{|l|}{ P value $=0,000$ Ho ditolak } \\
\hline
\end{tabular}

Tabel tersebut menunjukkan bahwa responden yang mempunyai pernafasan tidak teratur lebih tinggi (100\%) pada ibu bersalin dengan tekanan darah diastolik $>110 \mathrm{mmHg}$, dibandingkan dengan tekanan darah diastolik

90-110 (78,43\%) dan tekanan darah sistolik

$<90$ mmhg (24,80\%). Hasil uji Chi squere

dengan taraf signifikasi $5 \%$ diperoleh $p$ value

0,000 yang berarti bahwa nilai $\mathrm{p} \leq 0,05$, jadi Ho ditolak, sehingga kesimpulannya ada hubungan antara tekanan darah diastolik dengan pernafasan bayi baru lahir.

Hasil penelitian menunjukkan bahwa bayi baru lahri yang mempunyai pernafasan tidak teratur lebih tinggi $(100 \%)$ pada ibu bersalin dengan tekanan darah sistolik >160 mmHg, dibandingkan dengan tekanan darah sistolik 140-159 (85\%) dan tekanan darah sistolik <140 mmhg (33,11\%). Hasil uji Chi squere dengan taraf signifikasi 5\% diperoleh $p$ value 0,000 yang berarti bahwa nilai $\mathrm{p} \leq 0,05$, jadi Ho ditolak, sehingga kesimpulannya ada hubungan antara tekanan darah sistolik dengan pernafasan bayi baru lahir. Hal ini sejalan dengan penelitian Masyita, 2013 yang mengatakan bahwa hipertensi pada ibu hamil menyebabkan nilai APGAR turun termasuk dalam nilai APGAR adalah pernafasan.

Factor tekanan darah berpengaruh terhadap kualitas bayi yang dilahirkan. 
Rendahnya tekanan darah berpengaruh terhadap gangguan vaskular yang dapat mengakibatkan rendahnya asupan oksigen yang dialirkan ke janin, sehingga menyebabkan hipoksia intrauterine.

Tekanan darah yang tinggi (>140/90 mmhg) akan menyebabkan menurunnya perfusi jaringan uteroplasenta, pertukaran gas terganggu, vasospasme dan kerusakan sel endotel pembuluh darah plasenta sehingga menyebabkan hipoksia yang berakibat morbiditas bayi meningkat. Hal ini disebabkan karena Hipertensi ibu maupun hipotensi pada ibu (Sarwono, 2009), (Kristayanasari,2010).

Terdapat beberapa factor yang berperan terhadap kegagalan pernafasan bayi baru lahir yaitu;factor ibu, plasenta dan neonates.

\section{SIMPULAN}

1. Umur ibu terbanyak di rentang usia reproduksi sehat (20-35)yaitu $71.3 \%$ dibandingkan usia >35 tahun sebesar $20.7 \%$ dan $<20$ tahun sebesar $8 \%$.

2. Karakteristik responden berdasarkan paritas yang tertinggiadalah primipara $(77.0 \%)$ dibandingkan dengan multipara $(17.2 \%)$ dan Grandemultipara (5.7\%).

3. Keadaan sistolik ibu bersalin bahwa tekanan darah sistolik $<140 \mathrm{mmHg}$ lebih tinggi $85 \%$ dibandingkan dengan tekanan darah sistolik 140159 mmhg $11.5 \%$, tekanan darah sistolik >:160 mmhg adalah 3.4\%.

4. Keadaan diastolic ibu bersalin bahwatekanan diastolic < 90, ,Hg $\begin{array}{lll}\text { adalah } & 69.5 \% & \text { terbanyak }\end{array}$ dibandingkan tekanan darah diastolic 90-109 mmhg (29.3\%), dan >110 $\mathrm{mmHg}(1.1 \%)$.

5. Keadaan pernafasan bayi baru lahir teratur lebih tinggi $(58.6 \%)$ dibandingkan dengan nafas yang tidak teratur $(41.4 \%)$.

6. Terdapat hubungan tekanan darah sistolik dengan pernafasan bayi baru lahir

7. Terdapat hubungan tekanan darah diastolic dengan pernafasan bayi baru lahir

\section{SARAN}

1. Bagi peneliti selanjutnya

Perlu mengadakan penelitian tentang factor-faktor lain yang berpengaruh terhadap pernafasan bayi baru lahir dengan mengendalikan variabel pengganggu.

2. Bagi bidan

Bidan sebagai tenaga kesehatan memberikan layanan promotif mengenai kenaikan tekanan darah dan melakukan konsultasi serta pengawasan lebih intensif terhadap 
hasil pengukuran tekanan darah pada kasus hipertensi.

3. Bagi ibu bersalin

Bagi ibu yang akan bersalin harus selalu melakukan pemeriksaan ANC teratur dengan memperhatikan kondisi tekanan darah nya sehingga dapat diantisipasi untuk keadaan kegawatdaruratan.

\section{DAFTAR PUSTAKA}

Cunningham, F. Garry .2006. Obstetri Williams Edisi 21. Jakarta: EGC.

Dea, M. 2013. Hubungan Tekanan Darah Tinggi Pada Kehamilan dengan Asfiksia Bayi Baru Lahir di RS KU Muhammadiyah. Diakses dari repository.poltekkesmajapahit.ac.id

Faiqah, S. 2013. Hubungan Tekanan Darah Ibu dengan Berat Badan Lahir Rendah. Diakses dari http://www.lpsdimataram.com ISSN No. 1978-3787

JHPIEGO. 2003. Buku Panduan Praktis Pelayanan Kesehatan Maternal dan Neonatal. Jakarta. Yayasan Bina Pustaka Sarwono Prawirohardjo 
Nia J, et all. 2013. Pengaruh Hipotensi Terhadapapgar Score Bayi dengan $S C$ Dengan Anestesi Spinal di RSU Prof. DR. RD Kandou Manado Periode April - November 2013. Diakses dari ejournal.unsrat.ac.id

Putra, et all. 2014. Hubungan Persalinan Reterm Ada Preeklamsia Berat Dengan Fetal Outcome di RSU Islam Haraan Anda Tegal. Diakses dari Jurnal Kedokteran http: //www. jurnal.uii.ac.id

Pearce, Everlync. 2002. Anatomi dan Fisiologi untuk Para Medis. Jakarta: Gramedia

Seeley.2000. Anatomi dan Fisiologi. America : North Highend Education

Sloane.2003. Anatomi dan Fisiologi untuk Pemula. Jakarta : EGC

Sopiyudin. 2011. Teknik Analisa Data. Jakarta. EGC

Muliawati, Dyah. 2015. Hubungan Riwayat Hiertensi, Paritas, Umur Kehamilam Dan Anemia dengan Asfiksia Neonatorum Pada Ibu Bersalin Dengan Preeklamsi Berat. diakses dari http: www.uns.ac.id 
